\title{
Remote estimation of canopy nitrogen content in winter wheat using airborne hyperspectral reflectance measurements
}

\author{
Xianfeng Zhou ${ }^{\mathrm{a}, \mathrm{b}}$, Wenjiang Huang ${ }^{\mathrm{a}, *}$, Weiping Kong ${ }^{\mathrm{a}}$, Huichun $\mathrm{Ye}^{\mathrm{a}}$, Juhua Luo ${ }^{\mathrm{c}}$, \\ Pengfei Chen ${ }^{\mathrm{d}}$ \\ ${ }^{a}$ Key Laboratory of Digital Earth Science, Institute of Remote Sensing and Digital Earth, Chinese Academy of Science, Beijing 100094, China \\ ${ }^{\mathrm{b}}$ University of Chinese Academy of Sciences, Beijing 100049, China \\ ${ }^{\mathrm{c}}$ Key Laboratory of Watershed Geographic Sciences, Nanjing Institute of Geography and Limnology, Chinese Academy of Sciences, Nanjing 210008, China \\ ${ }^{\mathrm{d}}$ State Key Laboratory of Resources and Environment Information System, Institute of Geographic Science and Natural Resources Research of \\ Chinese Academy of Science, Beijing 100101, China
}

Received 17 September 2015; received in revised form 25 June 2016; accepted 27 June 2016

Available online 21 July 2016

\begin{abstract}
Timely and accurate assessment of canopy nitrogen content $(\mathrm{CNC})$ provides valuable insight into rapid and real-time nitrogen status monitoring in crops. A semi-empirical approach based on spectral index was extensively used for nitrogen content estimation. However, in many cases, due to specific vegetation types or local conditions, the applicability and robustness of established spectral indices for nitrogen retrieval were limited. The objective of this study was to investigate the optimal spectral index for winter wheat (Triticum aestivum L.) CNC estimation using Pushbroom Hyperspectral Imager (PHI) airborne hyperspectral data. Data collected from two different field experiments that were conducted during the major growth stages of winter wheat in 2002 and 2003 were used. Our results showed that a significant linear relationship existed between nitrogen and chlorophyll content at the canopy level, and it was not affected by cultivars, growing conditions and nutritional status of winter wheat. Nevertheless, it varied with growth stages. Periods around heading stage mainly worsened the relationship and CNC estimation, and CNC assessment for growth stages before and after heading could improve CNC retrieval accuracy to some extent. CNC assessment with PHI airborne hyperspectra suggested that spectral indices based on red-edge band including narrowband and broadband $\mathrm{CI}_{\text {red-edge, }}$ NDVI-like and $\mathrm{ND}_{705}$ showed convincing results in $\mathrm{CNC}$ retrieval. NDVI-like and $\mathrm{ND}_{705}$ were sensitive to detect $\mathrm{CNC}$ changes less than $5 \mathrm{~g} / \mathrm{m}^{2}$, narrowband and broadband $\mathrm{CI}_{\text {red-edge }}$ were sensitive to a wide range of $\mathrm{CNC}$ variations. Further evaluation of CNC retrieval using field measured hyperspectra indicated that NDVI-like was robust and exhibited the highest accuracy in $\mathrm{CNC}$ assessment, and spectral indices $\left(\mathrm{CI}_{\text {red-edge }}\right.$ and $\left.\mathrm{CI}_{\text {green }}\right)$ that established on narrow or broad bands showed no obvious difference in CNC assessment. Overall, our study suggested that NDVI-like was the optimal indicator for winter wheat $\mathrm{CNC}$ retrieval.
\end{abstract}

(C) 2016 COSPAR. Published by Elsevier Ltd. All rights reserved.

Keywords: Airborne hyperspectral; Spectral index; Canopy nitrogen content; Winter wheat

\footnotetext{
* Co-first and corresponding author. Fax: +86 1082178177.

E-mail addresses: zhouxf@radi.ac.cn (X. Zhou), huangwj@radi.ac.cn (W. Huang), kongwp@radi.ac.cn (W. Kong), yehc@radi.ac.cn (H. Ye), jhluo@niglas.ac.cn (J. Luo), pengfeichen-001@hotmail.com (P. Chen).
}

\section{Introduction}

Nitrogen $(\mathrm{N})$ is the most important element that affects growing conditions and yield of crops (Ladha et al., 2005). A sufficient supply of nitrogen is crucial to the biochemistry of plants (Clevers and Kooistra, 2012): nitrogen deficiency significantly diminishes the photosynthetic yield of 
crops (Feng et al., 2014), while excessive application of nitrogen fertilizer can cause environmental pollution (Ferguson et al., 2002; Hatfield et al., 2008; Inoue et al., 2012). Therefore, timely and accurate assessment of nitrogen status is critical in agricultural management so that the efficiency of nitrogen usage can be improved, thus ensuring a high grain yield while minimizing environmental damage (Tian et al., 2011). Traditional laboratory-based techniques are effective for diagnosing nitrogen status and making nitrogen fertilizer recommendations (Wu et al., 2007). However, these techniques are generally tedious, timeconsuming and destructive, and thus cannot be repeated many times in order to make a more representative evaluation of canopy nitrogen status in a particular field or in the fields of a given area (Lemaire, 1997).

Remote sensing technologies have proved to be a potential source for estimates of variables related to biophysical, physiological or biochemical characteristics (Hansen and Schjoerring, 2003). Within the visible and near infrared wave range $(400 \mathrm{~nm}-1000 \mathrm{~nm})$, the absorption features of leaf spectral reflectance are mainly dominated by plant pigments and effects of the leaf cell structure. Research has shown that the absorption features in the blue and red spectral regions is strongly correlated with leaf chlorophyll (Chl) content and a close correlation between foliar nitrogen and chlorophyll content has been reported for various crops such as wheat, maize and potatoes, which provides the bridge for leaf nitrogen estimation using spectral features in visible and near infrared wave range (Clevers and Kooistra, 2012; Oppelt and Mauser, 2004; Yoder and Pettigrew-Crosby, 1995). Although the relationship between nitrogen and chlorophyll contents at the canopy level forms the basis for canopy nitrogen content (CNC) assessment, limited attention have been focused on the relationship among published studies on CNC retrieval. Whether this relationship is dependent on species type, phenological stage, growing conditions and nutritional status (Clevers and Kooistra, 2012), and how the relationship affects CNC estimation need to be intensively studied in order for better understanding of $\mathrm{CNC}$ retrieval.

With remote sensing techniques, much progress in nitrogen content assessment have been made in agricultural crops (Clevers and Gitelson, 2013; Clevers and Kooistra, 2012; Inoue et al., 2012; Schlemmer et al., 2013). Among these researches, a semi-empirical method based on spectral indices are commonly used for their high computation efficiency and universality. Sims and Gamon (2002) proposed two hyperspectral indices including normalized difference $\left(\mathrm{ND}_{705}\right)$ and simple ratio $\left(\mathrm{SR}_{705}\right)$, and found that $\mathrm{ND}_{705}$ and $\mathrm{SR}_{705}$ were good estimators of chlorophyll and nitrogen content. Work conducted by Clevers and Kooistra (2012) indicated that the red-edge chlorophyll index $\left(\mathrm{CI}_{\text {red-edge }}\right)$ was linearly related to canopy chlorophyll content using PROSAIL simulations, and it was a good and linear estimator of canopy nitrogen content in both grassland and potato cropping systems. Based on the normalized difference vegetation index (NDVI) formula,
Darvishzadeh et al. (2011) developed an inspiring NDVIlike index with hyperspectral data, and it showed remarkable performance in crop variables assessment, such as LAI. Its capability and applicability in other variables retrieval, such as nitrogen and chlorophyll, deserves investigation. To acquire information on agronomic variables at regional scale, the capability of spectral index method in retrieval of crop chlorophyll and nitrogen using multispectral satellite data has been investigated. Clevers and Gitelson (2013) found that the $\mathrm{CI}_{\text {red-edge }}$, the green chlorophyll index $\left(\mathrm{CI}_{\text {green }}\right)$, and the MERIS terrestrial chlorophyll index (MTCI) were accurate and linear estimators of canopy chlorophyll and nitrogen contents by focusing on the potential of Sentinel-2 and Sentinel-3 satellites for crop parameters retrieval. Schlemmer et al. (2013) suggested that canopy chlorophyll and nitrogen content in maize could be accurately retrieved using $\mathrm{CI}_{\text {green }}$ and $\mathrm{CI}_{\text {red-edge }}$ based on near infrared, green and red-edge spectral bands of Sentinel-2 satellite. The above mentioned spectral indices established on hyperspectral (narrow) or multispectral (broad) bands indeed exhibited good performance in crop nitrogen and chlorophyll retrieval. Nevertheless, their universality and robustness, and whether these spectral indices established on broad or narrow bands affect their capability in $\mathrm{CNC}$ estimation need to be clear.

The development of airborne hyperspectral techniques offers valuable opportunities for agronomic variables retrieval. Airborne hyperspectral sensors could obtain abundant information related to canopy characteristics using numerous fine narrow bands within specific spectrum at regional scale, thus making it possible for rapid and realtime detection of crop variables. The aforementioned spectral indices have been proved to be good estimators for chlorophyll or nitrogen content assessment using field measured hyperspectral or satellite multispectral data. Nevertheless, their applicability in CNC assessment using airborne hyperspectral reflectance measurements is rarely reported. Comprehensive evaluation of these spectral indices in $\mathrm{CNC}$ retrieval based on airborne hyperspectral techniques could help to enhance the universality and robustness of these indices. Also, it could contribute to diagnosing nitrogen status in crops and provide basis for satellite remote sensing applications in agricultural production.

Therefore, the aim of the present study was to assess the estimation of $\mathrm{CNC}$ in winter wheat using spectral indices derived from airborne hyperspectral measurements. The specific objectives were to: (i) investigate the relationship between $\mathrm{CNC}$ and canopy chlorophyll content (CCC) and its influence on $\mathrm{CNC}$ estimation using multiple datasets obtained from field experiments conducted under different growing conditions and plant nutritional status; (ii) evaluate the predictive power of broadband and narrowband indices derived from airborne hyperspectral reflectance, that is, $\mathrm{ND}_{705}, \mathrm{SR}_{705}, \mathrm{MTCI}$, NDVI-like narrowband $\mathrm{CI}_{\text {red-edge }}$ and $\mathrm{CI}_{\text {green }}$, and broadband $\mathrm{CI}_{\text {red-edge }}$ and $\mathrm{CI}_{\text {green }}$ in winter wheat $\mathrm{CNC}$ retrieval. It 
was anticipated that the results of this study would help to provide a reference for real-time monitoring of the $\mathrm{CNC}$ in cereal crops.

\section{Materials and methods}

\subsection{Experimental design}

To achieve the mentioned objectives, two different field experiments carried out during 2002 and 2003 growing periods were used, as described below.

Experiment 1 (Exp. 1): this experiment was conducted in 2002 at the National Experimental Station for Precision Agriculture $\left(40^{\circ} 10^{\prime} \mathrm{N}, 116^{\circ} 27^{\prime} \mathrm{E}\right)$, Beijing, China. The field soil used was classified as silty clay loam. Three cultivars of winter wheat (9507, 9428 and Jingdong 8) were planted in 48 sampling plots that each in a size of $30 \mathrm{~m} \times 32.4 \mathrm{~m}$, where nitrogen fertilizer was applied at concentrations of $0,150,300$ and $450 \mathrm{~kg} \mathrm{ha}^{-1}$, with one third being applied at pre-planting, one third at tillering stage (Zadoks scale 20, Z20) and the remainder at stem elongation stage (Z30). Water was also applied in amounts of $0,225,450$ and $675 \mathrm{~m}^{3} \mathrm{ha}^{-1}$, with $50 \%$ being added at tillering stage (Z20) and $50 \%$ at elongation (Z30). The sampling dates included March 25 (tillering stage, Z25), April 2 (stem elongation, Z31), April 10 (stem elongation, Z34), April 18 (booting, Z41), May 5 (head emergence, Z54), May 17 (pollination, Z60), May 24 (pollination, Z68), and May 31 (milk development, Z73).

Experiment 2 (Exp. 2): several farmers' fields located in the Shunyi $\left(40^{\circ} 08^{\prime} \mathrm{N}, 116^{\circ} 39^{\prime} \mathrm{E}\right)$, Changping $\left(40^{\circ} 13^{\prime} \mathrm{N}, 116^{\circ}\right.$ $\left.12^{\prime} \mathrm{E}\right)$ and Fangshan $\left(\left(39^{\circ} 43^{\prime} \mathrm{N}, 115^{\circ} 59^{\prime} \mathrm{E}\right)\right)$ districts of Beijing were used for the field experiment carried out during 2003. Two major varieties of winter wheat (9507 and 9428) were grown in these fields, which were managed by local farmers. 21 sampling plots that had an area of $30 \mathrm{~m} \times 30 \mathrm{~m}$ and in which a single cultivar had been planted were chosen for field surveys that were conducted on March 30 (tillering, Z27), April 7 (stem elongation, Z33), April 15 (stem elongation, Z37), April 23 (booting, Z45), May 1 (head emergence, Z50), May 9 (head emergence, Z56), May 17 (pollination, Z60), May 25 (pollination, Z68) and June 2 (milk development, Z73).

\subsection{Data collection}

\subsubsection{Spectra measurements}

The canopy reflectance was measured using an ASD FieldSpec Pro spectrometer (Analytical Spectral Devices, Boulder, CO, USA) under clear, blue-sky conditions between 10:00 $\mathrm{h}$ and 14:00 $\mathrm{h}$ (Beijing Local Time). In each experiment, a $1 \mathrm{~m} \times 1 \mathrm{~m}$ area of crop was selected for measurement of the canopy reflectance and the measurements were obtained at a nadir position at approximately $1.3 \mathrm{~m}$ above the ground. The spectrometer was configured with a spectral range of 350 to $2500 \mathrm{~nm}$ and a field of view of $25^{\circ}$, and its spectral resolution (full width at half maxi- mum, FWHM) was $1.4 \mathrm{~nm}$ for the region 350 to $1050 \mathrm{~nm}$ and $2 \mathrm{~nm}$ for the region 1050 to $2500 \mathrm{~nm}$. The measured radiance was converted into reflectance by recording irradiance spectra from a $0.4 \mathrm{~m} \times 0.4 \mathrm{~m} \mathrm{BaSO}_{4}$ calibration panel. All radiance measurements were recorded as an average of 20 individual measurements (minus dark current) using an optimized integration time.

\subsubsection{Plant measurements}

In both experiment, the $1 \mathrm{~m} \times 1 \mathrm{~m}$ area of wheat samples were collected for biophysical and biochemical analysis after canopy spectra measurements. For each sample, all green leaves were separated from the stems. leaf area index (LAI)was determined with a dry weight method (Wang et al., 2005). Leaf segments of approximate area $0.06 \mathrm{~m}^{2}$ were cut from the central part of about 30 leaves selected as reference leaves for LAI calculation. Both reference leaves and the remaining leaves were oven-dried at $70{ }^{\circ} \mathrm{C}$ to constant weight and weighed. LAI was calculated as Eq. (1):

$\mathrm{LAI}=\frac{\mathrm{S}_{\mathrm{r}} \mathrm{W}_{\mathrm{t}}}{\mathrm{S}_{1} W_{\mathrm{r}}}$

where $S_{r}\left(m^{2}\right)$ is the area of the reference leaves, $W_{t}(g)$ is the total dry weight of the sampled leaves, $S_{1}$ is the sampled land area $\left(\mathrm{m}^{2}\right)$ and $\mathrm{W}_{\mathrm{r}}(\mathrm{g})$ is the dry weight of the reference leaves. Then specific leaf weight (SLW, $\mathrm{g} / \mathrm{m}^{2}$ ) was calculated from the dried weight and the area of the reference leaves.

After LAI and SLW determination, leaf samples were ground to pass through a 40-mesh screen. Leaf nitrogen concentration ( $\mathrm{LNC}, \%$ ) was determined by the Kjeldahl method (Bremner, 1960) with a B-339 distillation unit, and leaf chlorophyll concentration (LCC, $\mathrm{mg} / \mathrm{g}$ ) was obtained by the spectrophotometric method (Gao, 2006), Next, the $\mathrm{CNC}$ and $\mathrm{CCC}$ were calculated using the equations below (Zhao et al., 2012).

$$
\begin{aligned}
& \mathrm{CNC}=(\mathrm{LNC} \times \mathrm{LAI} \times \mathrm{SLW}) / 100 \\
& \mathrm{CCC}=(\mathrm{LCC} \times \mathrm{LAI} \times \mathrm{SLW}) / 100
\end{aligned}
$$

\subsubsection{Airborne campaigns}

Airborne hyperspectral images of the experimental fields were acquired using the Pushbroom Hyperspectral Imager (PHI) designed by the Shanghai Institute of Technical Physics of the Chinese Academy of Sciences and flown onboard a Yun-5 aircraft (Shijiazhuang Aircraft Manufacturing Company, China). The PHI sensor comprised a solid state, area array and silicon CCD device of $780 \times 244$ elements and had a spectral range of $400-850 \mathrm{~nm}$, with a field of view of $21^{\circ}$. Its spectral resolution was $5 \mathrm{~nm}$ and the sensor was able to obtain images in a nadir-pointing direction with a $1 \mathrm{~m} \times 1 \mathrm{~m}$ spatial resolution at an altitude of $1000 \mathrm{~m}$ above the ground. During the 2002 growing season, images were obtained at midday on April 18, May 17 and May 31. The images were radio- 
metrically and geometrically corrected using an array of georeferenced light and dark targets $(5 \mathrm{~m} \times 5 \mathrm{~m})$ located at the boundaries of the field site. The location of each target, as well as any field measurements were recorded using a differential global positioning system (Trimble Sunnyvale California, USA). In order to obtain the hyperspectral reflectance, radiometric correction was performed using the band by band moment matching method and the images were geometrically corrected using ground control points (Liu, 2002).

In addition, the PHI images were denoised with the Savitzky-Golay method to further improve the image quality (Xie et al., 2014). The denoised spectrum acquired with PHI sensor on April 18, May 17 and May 31 were presented in Fig. 1. In addition, the synchronous canopy reflectance obtained by ASD device were also indicated in Fig. 1. Comparison showed that the PHI spectrum were in good accordance with the ASD spectrum in the visible band $(400-760 \mathrm{~nm})$, which suggesting the feasibility of PHI spectrum for biochemical retrievals. However, differences existed in the reflectance value in the near-infrared bands $(780-850 \mathrm{~nm})$. This might be largely related with the noise ratio of the PHI sensor in the near-infrared wavelengths.

\subsection{Spectral indices}

In the present study, published spectral indices that made accurate estimation of nitrogen in previous studies were chosen to assess CNC in winter wheat with PHI airborne hyperspectra. These indices included $\mathrm{ND}_{705}, \mathrm{SR}_{705}$, MTCI, narrowband $\mathrm{CI}_{\text {red-edge }}$ and $\mathrm{CI}_{\text {green }}$. Meanwhile, the capability of broadband indices in CNC assessment were also investigated. Since the PHI sensor had a spectral range of $400-850 \mathrm{~nm}$, with a $5 \mathrm{~nm}$ spectral resolution, we resampled the PHI hyperspectra with Sentinel-2 spectral response function to obtain broadband spectra, and broadband $\mathrm{CI}_{\text {red-edge }}$ and $\mathrm{CI}_{\text {green }}$ indices were then calculated to make a comparison with narrowband $\mathrm{CI}_{\text {red-edge }}$ and $\mathrm{CI}_{\text {green }}$. In addition, the inspiring narrowband NDVI-like was also used for $\mathrm{CNC}$ assessment. It was calculated from the PHI reflectance spectra, using all possible
$112 \times 112=12544$ wavelength combinations between 405 and $835 \mathrm{~nm}$. The correlation coefficient $\left(R^{2}\right)$ between the NDVI-like and the measured CNC were computed. Band combinations that formed the optimal index were determined for CNC estimation based on the highest $R^{2}$ values. Details about these indices were shown in Table 1.

\subsection{Model evaluation}

To evaluate the performance of spectral indices in $\mathrm{CNC}$ retrieval, best-fit functions between spectral indices and $\mathrm{CNC}$ were developed. Sensitivity of different spectral indices to detect changes in $\mathrm{CNC}$ was then tested through the use of the noise equivalent (NE) as the method reported by (Viña and Gitelson, 2005) and (Viña et al., 2011). Moreover, a $k$-fold cross-validation procedure was used to validate the behavior of spectral indices using PHI hyperspectra in CNC assessment. In our case, the hyperspectra dataset (144 samples, of which 4 samples with 0 LAI value were left out) was randomly split into ten sets ( $k=10)$, and each set was estimated by the remaining samples. All the selected spectral indices were tested using the same $k$-fold partitions. This kind of validation was necessary because it reduced the dependence on a single random partition into calibration and validation datasets; also, it guaranteed that all samples were used for both training and validation with each sample used for validation exactly once. Then, the overall performance of these models were evaluated by statistics including coefficient of determination $\left(R^{2}\right)$, root mean square error (RMSE) and relative RMSE (RRMSE). $R^{2}$ reflects the strength of linear statistical correlation between variables, while RMSE and MAE indicate absolute estimation errors and RRMSE express the error in relative terms, allowing the comparisons between different variables. The equations for these statistics are:

$$
\begin{aligned}
& \mathrm{NE}=\frac{\mathrm{RMSE}\{\mathrm{VI} \text { vs } \cdot \mathrm{CNC}\}}{d(\mathrm{VI}) / d(\mathrm{CNC})} \\
& \mathrm{RMSE}=\sqrt{\frac{1}{n} \sum_{i=1}^{n}\left(V_{\mathrm{est}}^{i}-V_{\mathrm{obs}}^{i}\right)^{2}}
\end{aligned}
$$
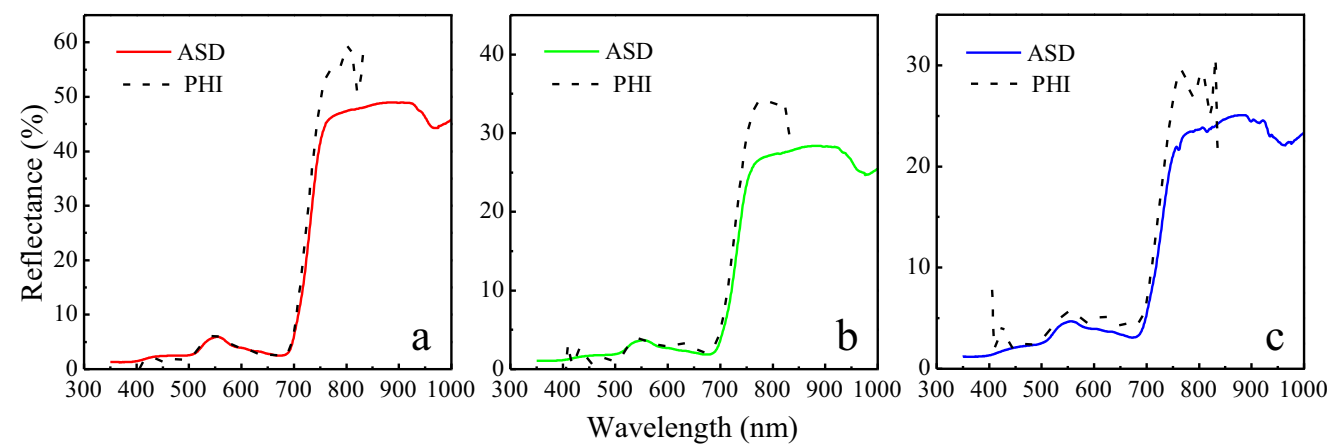

Fig. 1. Comparison of spectrum acquired with ASD device and PHI sensor. (a), (b) and (c) are the spectrum of Jingdong 8 cultivar of winter wheat acquired on April 18, May 17 and May 31, respectively. 
Table 1

Spectral indices investigated in this study.

\begin{tabular}{lll}
\hline Index & Equation & References \\
\hline $\mathrm{ND}_{705}$ & $\left(R_{750}-R_{705}\right) /\left(R_{750}+R_{705}\right)$ & Sims and Gamon (2002) \\
$\mathrm{SR}_{705}$ & $R_{750} / R_{705}$ & Sims and Gamon (2002) \\
$\mathrm{MTCI}$ & $\left(R_{753}-R_{708}\right) /\left(R_{708}-R_{681}\right)$ & Dash and Curran, (2004) \\
NDVI-like & $\left(R_{731}-R_{709}\right) /\left(R_{731}+R_{709}\right)$ & Darvishzadeh et al. (2011) \\
Narrowband $\mathrm{CI}_{\text {red-edge }}$ & $R_{783} / R_{705}-1$ & Gitelson et al. (2005) \\
Narrowband $\mathrm{CI}_{\text {green }}$ & $R_{783} / R_{560}-1$ & Gitelson et al. (2005) \\
Broadband $\mathrm{CI}_{\text {red-edge }}$ & $R_{783} / R_{705}-1$ & Gitelson et al. (2005), Clevers and Gitelson (2013) \\
Broadband $\mathrm{CI}_{\text {green }}$ & $R_{783} / R_{560}-1$ & Gitelson et al. (2005), Clevers and Gitelson (2013) \\
\hline
\end{tabular}

$R_{\lambda}$ refers to the reflectance at wavelength $\lambda \mathrm{nm}$. For narrowband CI calculation, bands of the PHI sensor were used, while for broadband CI, bands of the PHI that resampled to Sentinel-2 sensor were used.

$\operatorname{RRMSE}=100 \times \frac{\mathrm{RMSE}}{\mathrm{Mean}(\mathrm{obs})}$

where $d(\mathrm{VI}) / d(\mathrm{CNC})$ is the first derivative of the best-fit function of the relationship "vegetation index (VI) vs. CNC" with respect to canopy nitrogen content, while, RMSE is the root mean square error of the best-fit function of this relationship. The NE has the advantage of allowing the direct comparison among different spectral indices in dynamic ranges. $V_{\text {est }}^{i}$ and $V_{\text {obs }}^{i}$ are the estimated, observed $\mathrm{CNC}$ values, respectively, $\mathrm{n}$ is the number of samples.

\section{Results}

\subsection{Relationship between $C N C$ and $C C C$}

Relationship between chlorophyll and nitrogen was crucial, since crop nitrogen status could be accessed through chlorophyll estimates (Baret et al., 2007). Many studies suggested that crop nitrogen content was closely related with chlorophyll content, for instance, Ercoli et al. (1993) found a strong correlation between chlorophyll content and nitrogen content on a leaf-area basis. In the current study, linear relationship between $\mathrm{CNC}$ and $\mathrm{CCC}$ in winter wheat was found and this remarkable relationship was not affected by cultivars, growing conditions and nutritional status of winter wheat (Table 2). Nevertheless, the relation- ship did vary a little bit with growing stages. During the whole growth periods, the slope of the relationship between $\mathrm{CNC}$ and $\mathrm{CCC}$ shows an obvious decreasing tendency (Fig. 2a), and it remains constant from then until the milk development stage (Z73), when CNC and CCC stabilize. Reasons for this tendency could be explained that in early stages, such as tillering and stem elongation, nitrogen uptake exceeds the production of chlorophyll; with the advancement of growth periods, the consumption of a large amount of available nitrogen in biochemical reactions and the production of a large amount of chlorophyll cause the slope to decrease. It is worth noting that the heading stage (Z54) seems to be a boundary to separate the growth stages before and after heading, because slopes of the relationship exists great difference, which is more significant in stress condition (Exp. 1). This phenomenon might give a clue for CNC estimation separately for stages before and after heading to avoid the effect of heading stage.

In addition to the slope parameter, several interesting aspects were also observed in the coefficient of determination $\left(R^{2}\right)$ and standard error (SE) of the relationships. The $R^{2}$ for the relationship is the lowest during head emergence stage (Fig. 2b), and the SE value is the highest during the head emergence stage (Fig. 2c). Reasons for this might be that, apart from being consumed during the biochemical processes, nitrogen is also concentrated in the grains in stages such as head emergence and anthesis stages (Baret

Table 2

Relationships between $\mathrm{CNC}$ and $\mathrm{CCC}$ for various growth stages of winter wheat. The coefficient of determination $\left(R^{2}\right)$ and standard error (SE) of the relationships are indicated. The units of CNC, CCC and SE are $\mathrm{g} / \mathrm{m}^{2}$.

\begin{tabular}{|c|c|c|c|c|c|c|c|}
\hline \multicolumn{4}{|c|}{ Stressed condition (Exp. 1, $n=380$ ) } & \multicolumn{4}{|c|}{ Normal condition (Exp. 2, $n=189$ ) } \\
\hline Growth stage & N/Chl relationship & $R^{2}$ & SE N content & Growth stage & $\mathrm{N} / \mathrm{Chl}$ relationship & $R^{2}$ & SE $N$ content \\
\hline Z25 & $N=5.200 \times \mathrm{Chl}+0.124$ & 0.963 & 0.013 & Z27 & $N=4.367 \times \mathrm{Chl}+0.159$ & 0.949 & 0.016 \\
\hline Z31 & $N=3.080 \times \mathrm{Chl}+0.968$ & 0.884 & 0.065 & Z33 & $N=3.776 \times \mathrm{Chl}+0.294$ & 0.908 & 0.061 \\
\hline Z34 & $N=3.544 \times \mathrm{Chl}+1.352$ & 0.805 & 0.157 & Z37 & $N=3.707 \times \mathrm{Chl}+0.821$ & 0.873 & 0.094 \\
\hline Z41 & $N=3.107 \times \mathrm{Chl}+1.328$ & 0.739 & 0.193 & Z45 & $N=2.878 \times \mathrm{Chl}+2.024$ & 0.725 & 0.210 \\
\hline \multirow[t]{2}{*}{$\mathrm{Z} 54$} & $N=2.250 \times \mathrm{Chl}+1.688$ & 0.773 & 0.233 & $\mathrm{Z} 50$ & $N=2.842 \times \mathrm{Chl}+1.703$ & 0.716 & 0.407 \\
\hline & & & & Z56 & $N=3.339 \times \mathrm{Chl}+0.766$ & 0.828 & 0.194 \\
\hline $\mathrm{Z} 60$ & $N=2.479 \times \mathrm{Chl}+0.725$ & 0.862 & 0.215 & Z60 & $N=2.483 \times \mathrm{Chl}+1.740$ & 0.753 & 0.266 \\
\hline Z68 & $N=2.323 \times \mathrm{Chl}+0.801$ & 0.832 & 0.047 & Z68 & $N=2.750 \times \mathrm{Chl}+0.563$ & 0.870 & 0.126 \\
\hline $\mathrm{Z73}$ & $N=2.429 \times \mathrm{Chl}+0.547$ & 0.776 & 0.083 & $\mathrm{Z73}$ & $N=2.284 \times \mathrm{Chl}+0.679$ & 0.892 & 0.044 \\
\hline All & $N=2.841 \times \mathrm{Chl}+0.984$ & 0.801 & 0.399 & All & $N=3.270 \times \mathrm{Chl}+0.691$ & 0.866 & 0.307 \\
\hline
\end{tabular}



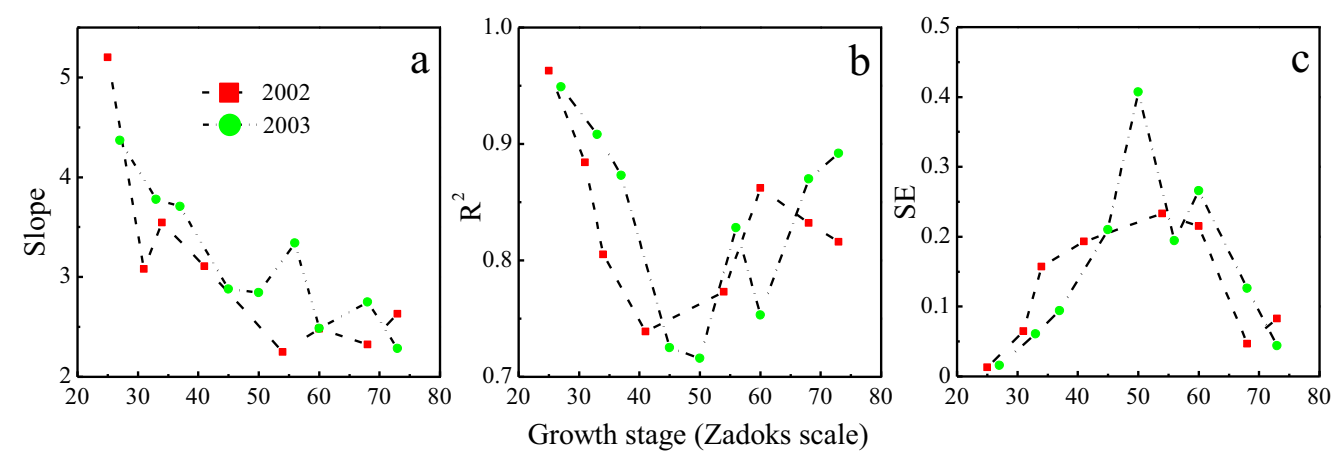

Fig. 2. Variation of slope, $R^{2}$ and $\mathrm{SE}$ of the relationships between $\mathrm{CNC}$ and $\mathrm{CCC}$ during the whole growth stages.

et al., 2007) and this may have disrupted the relationship between CNC and CCC. To further investigate the relationship between winter wheat $\mathrm{CNC}$ and growth stages, the average CNC, Standard deviation (SD) and Coefficient of variance $(\mathrm{CV})$ of $\mathrm{CNC}$ for various growth stages are shown in Fig. 3. With the advance of growth stages, the Average $\mathrm{CNC}$ and $\mathrm{SD}$ value of $\mathrm{CNC}$ in winter wheat offer a trend of rise first then fall, the value comes to the maximum when heading stage occurs; while the situation for $\mathrm{CV}$ value is the opposite. The $\mathrm{CV}$ value of $\mathrm{CNC}$ represents the discrete degree of $\mathrm{CNC}$ value, the smaller the $\mathrm{CV}$ value, the more aggregated the $\mathrm{CNC}$ value, this could explain the reason that $R^{2}$ between $\mathrm{CNC}$ and $\mathrm{CCC}$, and $R^{2}$ between $\mathrm{CNC}$ and spectral index around heading stage are rather low (Fig. 3). To sum up, even though growth stages affect the relationship between $\mathrm{CNC}$ and $\mathrm{CCC}$, and the variation of CNC content in winter wheat to some extent, the significant linear relationship between $\mathrm{CNC}$ and $\mathrm{CCC}$ and its immune to cultivars, growing conditions and nutritional status that found in present study could provide a crucial connection for winter wheat $\mathrm{CNC}$ estimation using spectral absorption features of chlorophyll.

\subsection{Assessment of CNC using airborne hyperspectral data}

The best-fit models of the selected spectral indices vs. $\mathrm{CNC}$ are shown in Fig. 4. Results suggest that narrowband $\mathrm{CI}_{\text {red-edge }}$ index best captures the canopy nitrogen content, with the highest determination coefficient $\left(R^{2}=0.771\right)$, then followed by broadband $\mathrm{CI}_{\text {red-edge }}\left(R^{2}=0.768\right)$ and NDVI-like $\left(R^{2}=0.759\right)$. ND 705 and NDVI-like indices exhibit logarithmic relationship with $\mathrm{CNC}$, and their relationship with $\mathrm{CNC}$ shows a high convergence of the points (Fig. 4). In contrast, relationships between $\mathrm{CNC}$ vs. $\mathrm{SR}_{705}$, MTCI, narrowband $\mathrm{CI}_{\text {red-edge, }}$ narrowband $\mathrm{CI}_{\text {green }}$, broadband $\mathrm{CI}_{\text {red-edge }}$ and broadband $\mathrm{CI}_{\text {green }}$ all follow a power function. With the best-fit models, sensitivity of the eight spectral indices to $\mathrm{CNC}$ variations was tested through the use of NE $\triangle \mathrm{CNC}$. Results in Fig. 5 show that indices behave differently to $\mathrm{CNC}$ variations. NDVI-like and $\mathrm{ND}_{705}$ have the smallest $\mathrm{NE} \Delta \mathrm{CNC}$ values when $\mathrm{CNC}$ is less than $4 \mathrm{~g} / \mathrm{m}^{2}$. Nevertheless, NE $\Delta \mathrm{CNC}$ values of these two indices are linearly related to $\mathrm{CNC}$ variations. For $\mathrm{SR}_{705}$ and MTCI, their NE $\Delta \mathrm{CNC}$ values are larger than that of NDVI-like and $\mathrm{ND}_{705}$ when $\mathrm{CNC}$ is less than $5 \mathrm{~g} / \mathrm{m}^{2}$; however, the case is the contrary when $\mathrm{CNC}$ exceeds $5 \mathrm{~g} / \mathrm{m}^{2}$. This indicates that normalized difference indices (NDVI-like and $\mathrm{ND}_{705}$ ) might be sensitive to detect small CNC changes $\left(<5 \mathrm{~g} / \mathrm{m}^{2}\right)$, but vulnerable to saturate at high $\mathrm{CNC}$ values. $\mathrm{CI}_{\text {green }}$ and $\mathrm{CI}_{\text {red-edge }}$ show rather low $\mathrm{NE} \triangle \mathrm{CNC}$ values responded to $\mathrm{CNC}$ changes, and the behavior of $\mathrm{NE} \triangle \mathrm{CNC}$ for $\mathrm{CI}_{\text {red-edge }}$ is nearly invariant through the entire range of $\mathrm{CNC}$ variation, suggesting that $\mathrm{CI}_{\text {red-edge }}$ is less affected by saturation caused by $\mathrm{CNC}$ variations, this accords with the view of Clevers and Kooistra (2012).

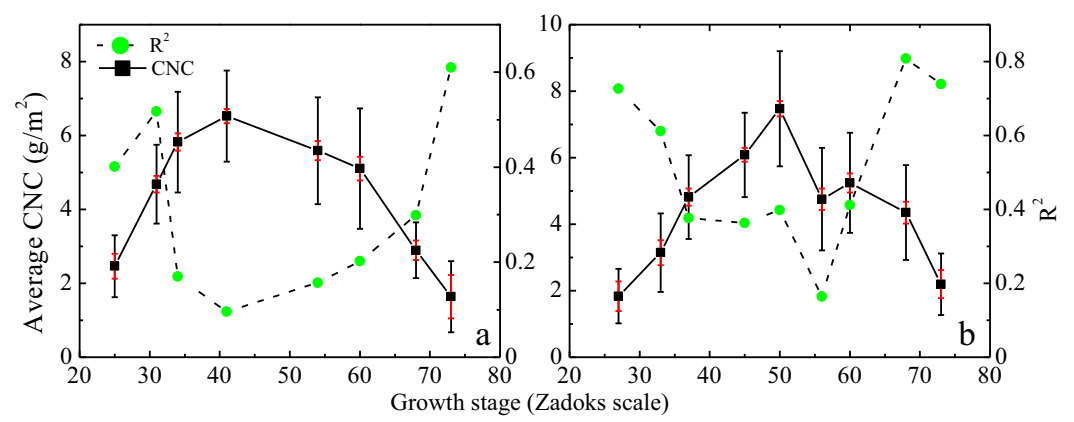

Fig. 3. Average CNC, standard deviation (black bar) and coefficient of variance (red bar) of CNC for various growth stages in 2002 (a) and 2003 (b); $R^{2}$ between NDVI-like index and CNC for various growth stages are also indicated. (For interpretation of the references to color in this figure legend, the reader is referred to the web version of this article.) 

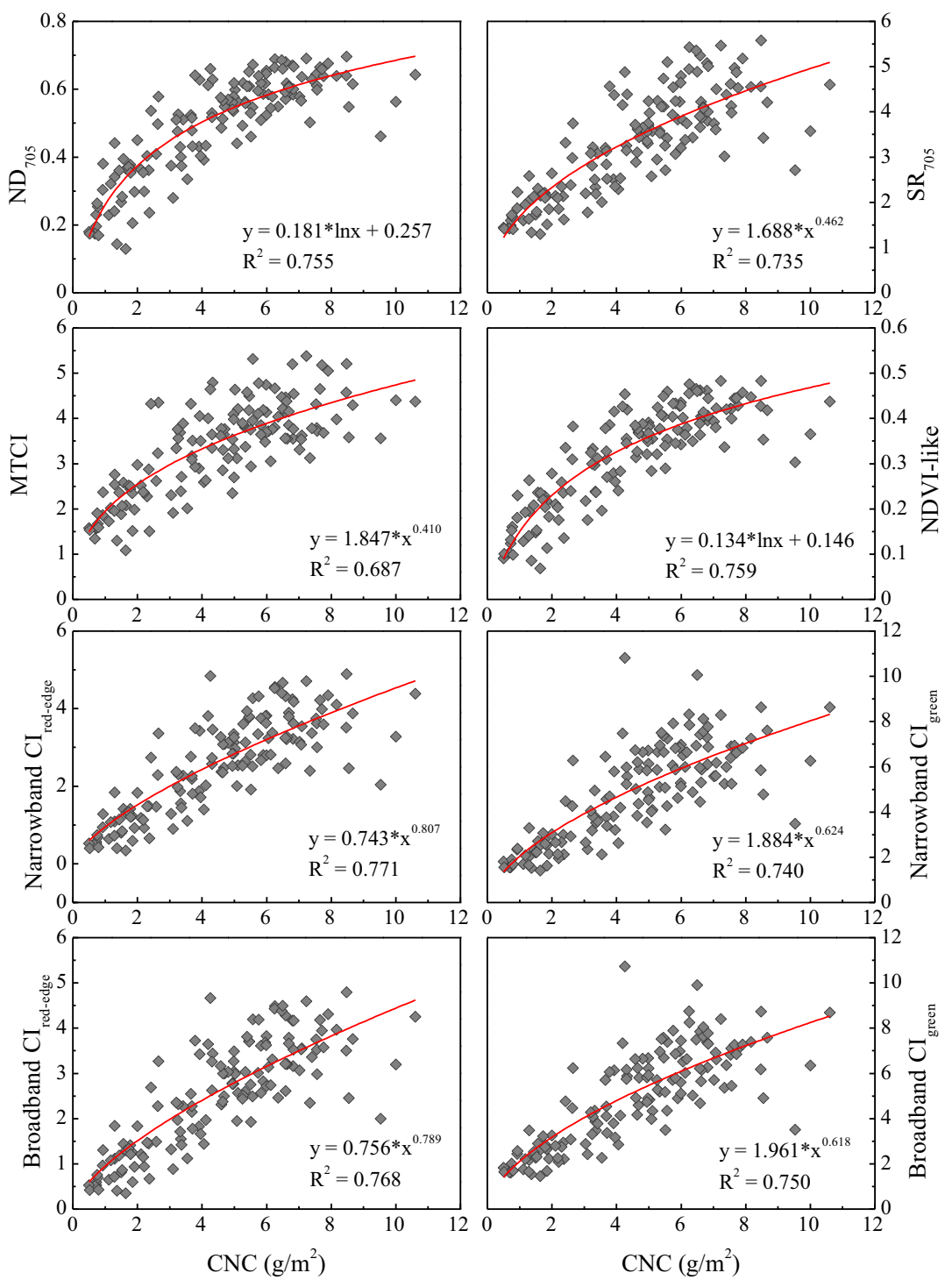

Fig. 4. Best-fit models between the selected spectral indices and CNC $(n=140)$.

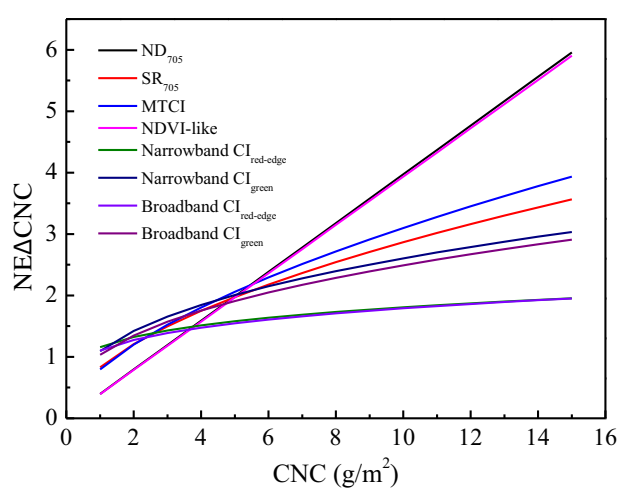

Fig. 5. Noise equivalent of $\mathrm{CNC}$ estimation by the spectral indices.

Performance of spectral indices in CNC assessment were then validated with a 10 -fold cross-validation strategy using best-fit functions between spectral indices and CNC. The final cross-validation results were determined by averaging the 10 sets' validation results. The results (Fig. 6) suggest that behaviors of spectral indices in CNC assessment varies. Results established on narrowband $\mathrm{CI}_{\text {red-edge }}$ show the highest accuracy $\left(R^{2}=0.627\right.$, $\mathrm{RMSE}=1.400 \mathrm{~g} / \mathrm{m}^{2}, \mathrm{RRMSE}=30.761 \%$ ), then followed by broadband $\mathrm{CI}_{\text {red-edge, }}, \mathrm{ND}_{705}, \mathrm{NDVI}$-like and others. Compared with $\mathrm{ND}_{705}, \mathrm{SR}_{705}$ is less accurate for $\mathrm{CNC}$ estimation. Broadband $\mathrm{CI}_{\text {red-edge }}$ exhibits nearly the same results with that of narrowband $\mathrm{CI}_{\text {red-edge, }}$ while, broadband $\mathrm{CI}_{\text {green }}$ shows even better accuracy than that of narrowband $\mathrm{CI}_{\text {green }}$. For broadband $\mathrm{CI}_{\text {green }}$ index, band $560 \mathrm{~nm}$ is the center wavelength and it has a $30 \mathrm{~nm}$ spectral width. This might help to add more spectral information than narrowband $560 \mathrm{~nm}$, thus increasing the estimation accuracy of broadband $\mathrm{CI}_{\text {green }}$. On the whole, spectral indices that established on red-edge band, such as narrowband and broadband $\mathrm{CI}_{\text {red-edge, }}$ NDVI-like, and $\mathrm{ND}_{705}$, showed excellent results in CNC estimation. Generally, pure chlorophyll $a$ and $b$ have absorption peaks at blue 

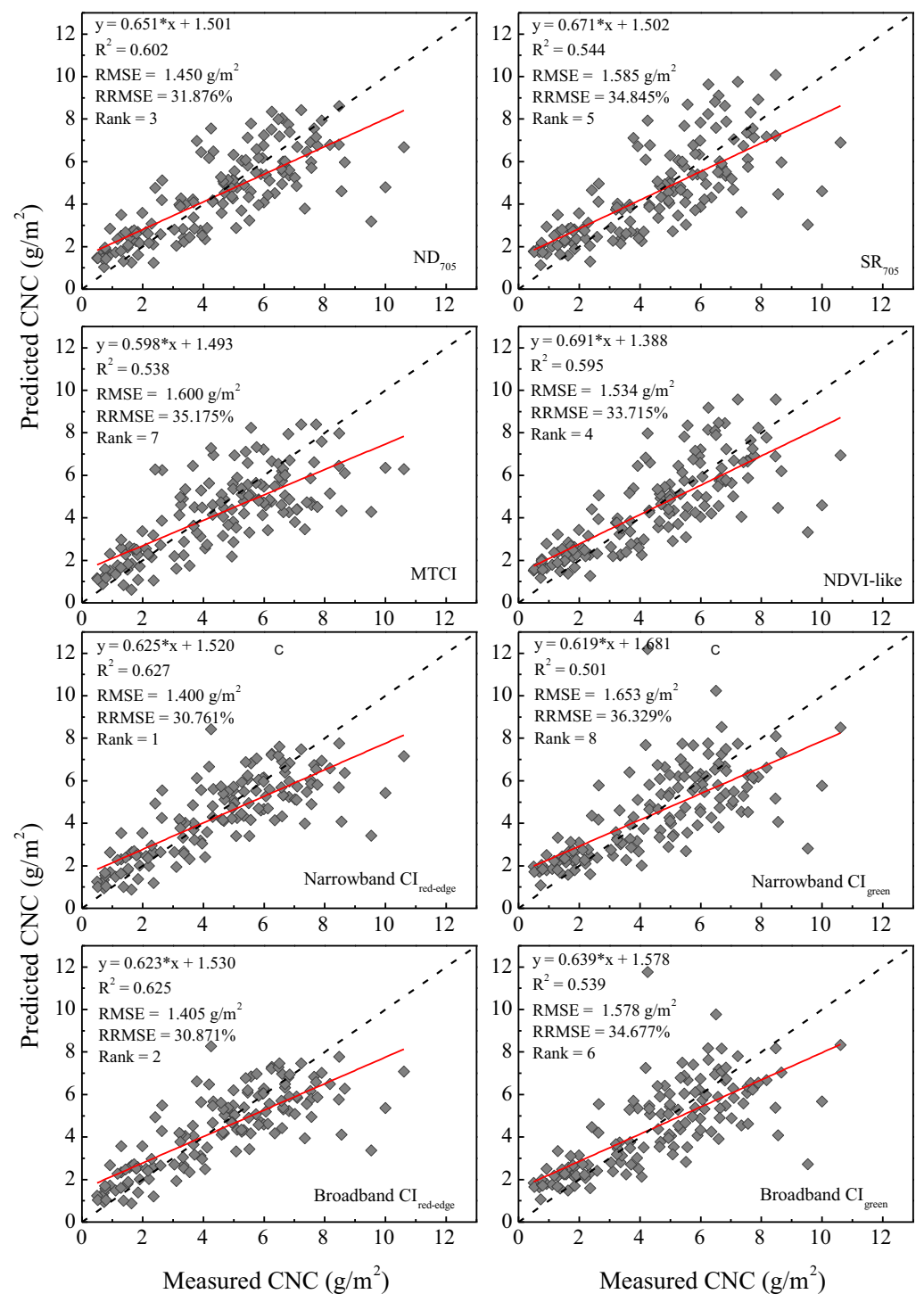

Fig. 6. Scatter plots of predicted CNC vs. measured CNC. Solid red lines indicate linear fit lines $(n=140)$. (For interpretation of the references to color in this figure legend, the reader is referred to the web version of this article.)

and red waveband regions, respectively $(430 \mathrm{~nm}$ and $662 \mathrm{~nm}$ for Chl $a ; 425 \mathrm{~nm}$ and $644 \mathrm{~nm}$ for Chl $b$ ). Nevertheless, within flesh leaves, the absorption peaks might shift toward longer wavelengths due to interactions between chlorophyll molecules and the surrounding molecules such as protein, liquid and water (Nobel, 2009). Inoue et al. (2012) pointed out that the degree of the shift was about $10-50 \mathrm{~nm}$ as affected by the physiological status and the ratio between chlorophyll $a$ and $b$, and the absorption peak of chlorophyll at red band region might affect the red edge reflectance. Consequently, the red edge bands (700$750 \mathrm{~nm}$ ) played a critical role in chlorophyll or nitrogen content estimation. Our current study results support this view as well.

The scatter plots of predicted $\mathrm{CNC}$ and measured $\mathrm{CNC}$ in Fig. 6 were further investigated to evaluate the $\mathrm{CNC}$ estimation with PHI airborne hyperspectra. Among the spectral indices, narrowband and broadband $\mathrm{CI}_{\text {red-edge }}$,
$\mathrm{ND}_{705}$ and NDVI-like showed rather high convergence to the 1:1 line, which was consistent with their high accuracy in $\mathrm{CNC}$ retrieval. $\mathrm{SR}_{705}$ and MTCI showed good estimate of CNC with $R^{2}$ higher than 0.530 and RMSE less than $1.600 \mathrm{~g} / \mathrm{m}^{2}$. Contrast to narrowband $\mathrm{CI}_{\text {green }}$, performance of broadband $\mathrm{CI}_{\text {green }}$ showed a slight improvement. Nevertheless, different from the scatters of other indices vs. CNC, one sample point showed obvious deviation from the scatters of both narrowband and broadband $\mathrm{CI}_{\text {green }}$ vs. $\mathrm{CNC}$, which indicates that $\mathrm{CI}_{\text {green }}$ index might be less stable than other indices. Among all the indices, several samples that had CNC larger than $8 \mathrm{~g} / \mathrm{m}^{2}$ were severely underestimated. This underestimation suggests that all these spectral indices could be prone to saturate when $\mathrm{CNC}$ value gets higher than $8 \mathrm{~g} / \mathrm{m}^{2}$. To sum up, even though spectral indices behaved differently, satisfactory estimating results could be achieved by spectral indices methods in CNC retrieval, indicating that it is feasible and practicable to assess winter 
wheat $\mathrm{CNC}$ with spectral indices derived from PHI airborne hyperspectral data.

\subsection{Evaluation of spectral indices in $C N C$ retrieval}

Field measured hyperspectra and corresponding CNC of winter wheat that collected from the whole growth cycle in 2002 and 2003 were used to further evaluate the robustness of the selected spectral indices in CNC retrieval. The measured hyperspectra were resampled based on PHI spectral response function to keep consistent with the spectral resolution of PHI sensor. Meanwhile, we also resampled the hyperspectral dataset with Sentinel-2 spectral response function to obtain broad band spectral reflectance for broadband $\mathrm{CI}_{\text {red-edge }}$ and $\mathrm{CI}_{\text {green }}$ calculation. Then, sampling data from 2002 were used for model calibration through developing best-fit functions, while data from 2003 were used for model validation. In calibration results (Table 3), the best-fit models for spectral vs. CNC relationships are all power function. NDVI-like shows the best accuracy $\left(R^{2}=0.657, \quad\right.$ RMSE $=1.309 \mathrm{~g} / \mathrm{m}^{2}$, RRMSE $=29.837 \%$ ), then followed by $\mathrm{ND}_{705}$ and others. Calibration model developed by MTCI shows the highest determination coefficient $\left(R^{2}=0.681\right)$, nevertheless, it has the lowest accuracy (RMSE $=1.475 \mathrm{~g} / \mathrm{m}^{2}$, RRMSE $=33.620 \%$ ). Narrowband and broadband $\mathrm{CI}_{\text {red-edge }}$ show the same results, while broadband $\mathrm{CI}_{\text {green }}$ exhibits better accuracy than narrowband $\mathrm{CI}_{\text {green }}$ in calibration results.

Validation results in Table 4 show that NDVI-like index exhibits the highest accuracy $\left(R^{2}=0.659\right.$, RMSE $=1.221 \mathrm{~g} / \mathrm{m}^{2}, \mathrm{RRMSE}=27.824 \%$ ), then followed by $\mathrm{ND}_{705}$ and broadband $\mathrm{CI}_{\text {green }}$. In CNC assessment with PHI hyperspectra, NDVI-like and $\mathrm{ND}_{705}$ also showed good accuracy. Their excellent performance in CNC estimation with field measured hyperspectra (Rank 1 and Rank 2 in both calibration and validation results) suggests that they are robust and accurate in $\mathrm{CNC}$ estimation using various hyperspectral datasets. Comparing the behavior of $\mathrm{ND}_{705}$ and $\mathrm{SR}_{705}$ in CNC estimation with both PHI airborne hyperspectra (Fig. 6) and field measured hyperspectra (Tables 3 and 4), we could find that $\mathrm{ND}_{705}$ showed better estimation accuracy than $\mathrm{SR}_{705}$. These two indices were composed by 750 and $705 \mathrm{~nm}$, but with different for- mations. Their varied performance suggests that indices of normalized difference formation $\left(\mathrm{ND}_{705}\right)$ might be more accurate than that of simple ratio form $\left(\mathrm{SR}_{705}\right)$ for $\mathrm{CNC}$ retrieval. In validation results, broadband $\mathrm{CI}_{\text {red-edge }}$ and narrowband $\mathrm{CI}_{\text {red-edge }}$ showed nearly the same results, while broadband $\mathrm{CI}_{\text {green }}$ behaved even better than narrowband $\mathrm{CI}_{\text {green. }}$. The performance of narrowband and broadband indices in $\mathrm{CNC}$ estimation with field measured hyperspectra indicates that spectral indices $\left(\mathrm{CI}_{\text {red-edge }}\right.$ and $\left.\mathrm{CI}_{\text {green }}\right)$ that established on narrow or broad bands show no obvious difference in $\mathrm{CNC}$ retrieval.

\section{Discussion}

In the present study, we confirmed a significant linear relationship between $\mathrm{CNC}$ and CCC in winter wheat, which made it possible for $\mathrm{CNC}$ estimation using spectral features in visible and near-infrared wave range. Moreover, we found that the relationship was unacted on the cultivars, growing conditions and nutritional status of winter wheat. Nevertheless, the relationship did vary a little bit with growing stages, and the periods around heading stage severely affected the relationship: $R^{2}$ for the relationship was low and SE value was high when heading stage occurred (Table 2 and Fig. 2). Changes of winter wheat $\mathrm{CNC}$ demonstrated that the periods around heading stage influenced the variation of $\mathrm{CNC}$ : the average $\mathrm{CNC}$ was the highest and $\mathrm{CV}$ of $\mathrm{CNC}$ was the lowest when heading stage approached (Fig. 3). Correlation between $\mathrm{CNC}$ with NDVI-like index indicated that the periods around heading stage severely affected the CNC retrieval: $R^{2}$ for the correlation is the lowest when heading stage occurred (Fig. 3). All of these analysis indicated that the $\mathrm{CNC} / \mathrm{CCC}$ relationship and CNC retrieval were influenced by growth stages, especially by the periods around heading stage. Given that the slopes of $\mathrm{CNC} / \mathrm{CCC}$ relationship varied obviously for stages before and after heading (Table 2), we conducted $\mathrm{CNC}$ estimation for growth stages before and after heading stage using NDVI-like index (Table 5). Compared with the performance of NDVI-like in calibration (Table 3) and validation (Table 4), estimating results of CNC for growth stages before heading showed great improvement (Table 5); while results of CNC for growth stages after heading showed satisfactory results in accord with that in Tables

Table 3

Calibration results of $\mathrm{CNC}\left(\mathrm{g} / \mathrm{m}^{2}\right)$ using the whole dataset obtained in $2002(n=380)$.

\begin{tabular}{|c|c|c|c|c|c|}
\hline Index & Rank & Model equation & $R^{2}$ & $\operatorname{RMSE}\left(\mathrm{g} / \mathrm{m}^{2}\right)$ & RRMSE $(\%)$ \\
\hline $\mathrm{ND}_{705}$ & 2 & $y=10.827 x^{1.539}$ & 0.641 & 1.323 & 30.168 \\
\hline $\mathrm{SR}_{705}$ & 7 & $y=0.875 x^{1.539}$ & 0.620 & 1.446 & 32.965 \\
\hline MTCI & 8 & $y=0.557 x^{1.462}$ & 0.681 & 1.475 & 33.620 \\
\hline NDVI-like & 1 & $y=18.403 x^{1.407}$ & 0.657 & 1.309 & 29.837 \\
\hline Narrowband $\mathrm{CI}_{\text {red-edge }}$ & 3 & $y=1.813 x^{0.784}$ & 0.618 & 1.407 & 32.078 \\
\hline Narrowband $\mathrm{CI}_{\text {green }}$ & 6 & $y=0.974 x^{0.942}$ & 0.581 & 1.433 & 32.676 \\
\hline Broadband $\mathrm{CI}_{\text {red-edge }}$ & 4 & $y=1.815 x^{0.791}$ & 0.617 & 1.407 & 32.084 \\
\hline Broadband $\mathrm{CI}_{\text {green }}$ & 5 & $y=0.964 x^{0.926}$ & 0.584 & 1.428 & 32.548 \\
\hline
\end{tabular}

Note: the Rank was a comprehensive evaluation based on $R^{2}$, RMSE and RRMSE, the same below. 
Table 4

Validation results of CNC $\left(\mathrm{g} / \mathrm{m}^{2}\right)$ using the whole dataset acquired in $2003(n=189)$.

\begin{tabular}{|c|c|c|c|c|c|}
\hline Index & Rank & Model equation & $R^{2}$ & $\operatorname{RMSE}\left(\mathrm{g} / \mathrm{m}^{2}\right)$ & RRMSE (\%) \\
\hline $\mathrm{ND}_{705}$ & 2 & $y=0.659 x+1.614$ & 0.644 & 1.236 & 28.179 \\
\hline $\mathrm{SR}_{705}$ & 7 & $y=0.781 x+1.327$ & 0.631 & 1.362 & 31.046 \\
\hline MTCI & 8 & $y=0.733 x+1.343$ & 0.511 & 1.587 & 36.180 \\
\hline NDVI-like & 1 & $y=0.682 x+1.587$ & 0.659 & 1.221 & 27.824 \\
\hline Narrowband $\mathrm{CI}_{\text {red-edge }}$ & 6 & $y=0.733 x+1.350$ & 0.631 & 1.293 & 29.465 \\
\hline Narrowband $\mathrm{CI}_{\text {green }}$ & 4 & $y=0.733 x+1.215$ & 0.636 & 1.269 & 28.934 \\
\hline Broadband $\mathrm{CI}_{\text {red-edge }}$ & 5 & $y=0.732 x+1.355$ & 0.632 & 1.291 & 29.423 \\
\hline Broadband $\mathrm{CI}_{\text {green }}$ & 3 & $y=0.736 x+1.215$ & 0.642 & 1.259 & 28.700 \\
\hline
\end{tabular}

Table 5

$\mathrm{CNC}$ estimating results for stages before and after heading stage with NDVI-like index $(n=569)$.

\begin{tabular}{|c|c|c|c|c|c|}
\hline Growth stages & $n$ & Model equation & $R^{2}$ & $\operatorname{RMSE}\left(\mathrm{g} / \mathrm{m}^{2}\right)$ & RRMSE $(\%)$ \\
\hline \multirow[t]{2}{*}{ Stages before heading } & 192 & $y=18.282 x^{1.252}$ & 0.784 & 1.041 & 21.357 \\
\hline & 84 & $y=0.886 x+0.966$ & 0.804 & 1.022 & 25.761 \\
\hline \multirow[t]{2}{*}{ Stages after heading } & 188 & $y=20.419 x^{1.662}$ & 0.730 & 1.259 & 32.393 \\
\hline & 105 & $y=0.512 x+2.193$ & 0.580 & 1.371 & 28.991 \\
\hline
\end{tabular}

3 and 4. This implies that $\mathrm{CNC}$ estimating for growth stages before and after heading could relieve the effect of heading stage on $\mathrm{CNC}$ retrieval to some extent.

The method applied in this study that combining measured $\mathrm{CNC}$ with spectral indices derived from PHI hyperspectra has further demonstrated the feasibility for extracting $\mathrm{CNC}$ in winter wheat using airborne hyperspectral data. Among the selected spectral indices, spectral indices established on red-edge band that including narrowband and broadband $\mathrm{CI}_{\text {red-edge, }}$ NDVI-like and $\mathrm{ND}_{705}$ showed convincing results in CNC retrieval using PHI airborne hyperspectra (Fig. 6). NDVI-like and $\mathrm{ND}_{705}$ might be sentive to detect low $\mathrm{CNC}$ values, while narrowband and broadband $\mathrm{CI}_{\text {red-edge }}$ were sensitive to a wide range of $\mathrm{CNC}$ changes. Further evaluation of the selected spectral indices in $\mathrm{CNC}$ assessment using the whole 2002 and 2003 field measured spectral data suggested that the robustness of spectral indices still varied. NDVI-like was robust and showed the best accuracy in $\mathrm{CNC}$ estimation using field measured spectral data (Tables 4 and 5), suggesting that NDIV-like was the optimal indicator for $\mathrm{CNC}$ assessment. Comparison between narrowband and broadband spectral indices in $\mathrm{CNC}$ estimation suggested that narrowband indices $\left(\mathrm{CI}_{\text {red-edge }}\right.$ and $\left.\mathrm{CI}_{\text {green }}\right)$ showed no better accuracy than broadband indices in $\mathrm{CNC}$ assessment, and broadband $\mathrm{CI}_{\text {red-edge }}$ and $\mathrm{CI}_{\text {green }}$ were suitable for $\mathrm{CNC}$ retrieval. However, there were still shortcomings in this study. During the growth stages, the obtained canopy reflectance of winter wheat could be affected by multiple factors, the effect of crop background (soil, crop residue, etc.) and plant features (LAI, leaf angle, etc.) on spectra response and $\mathrm{CNC}$ retrieval should be quantified and clarified for future studies.

\section{Conclusions}

This study aimed to evaluate the estimation of $\mathrm{CNC}$ in winter wheat using spectral indices derived from airborne hyperspectral measurements. Two field survey datasets acquired in 2002 and 2003 during the major growth stages of winter wheat were used to investigate the relationship between $\mathrm{CNC}$ and CCC. The PHI airborne hyperspectral imagery obtained corresponding to experiment in 2002 were employed for $\mathrm{CNC}$ assessment using semi-empirical methods based on spectral indices including $\mathrm{ND}_{705}$, $\mathrm{SR}_{705}$, MTCI, NDVI-like, narrowband and broadband $\mathrm{CI}_{\text {red-edge, }}$, and narrowband and broadband $\mathrm{CI}_{\text {green }}$. Then the whole 2002 and 2003 field data were used to further investigate the robustness and applicability of these indices in $\mathrm{CNC}$ retrieval.

Our main findings were that a significant linear correlation existed between $\mathrm{CNC}$ and $\mathrm{CCC}$, which provided a bridge for $\mathrm{CNC}$ assessment using spectral features in the visible and near-infrared wave range. Moreover, this relationship was not affected by cultivars, growing conditions and nutritional status of winter wheat. Nevertheless, it varied with growth periods, and the periods around heading stage mainly affected the relationship and CNC estimation. Sensitivity to CNC variations suggested that NDVI-like and $\mathrm{ND}_{705}$ might be sensitive to detect small $\mathrm{CNC}$ changes $\left(<5 \mathrm{~g} / \mathrm{m}^{2}\right)$, but vulnerable to saturate at high CNC values, while narrowband and broadband $\mathrm{CI}_{\text {red-edge }}$ were sensitive to a wide range of $\mathrm{CNC}$ changes. $\mathrm{CNC}$ assessment using PHI hyperspectra suggested that spectral indices based on red-edge band including narrowband and broadband $\mathrm{CI}_{\text {red-edge }}$, NDVI-like and $\mathrm{ND}_{705}$ showed convincing results in $\mathrm{CNC}$ retrieval. Evaluation of spectral indices in $\mathrm{CNC}$ assessment with field measured hyperspectra indicated that NDVI-like was robust and accurate for CNC estimation using various hyperspectral datasets. Spectral indices $\left(\mathrm{CI}_{\text {red-edge }}\right.$ and $\left.\mathrm{CI}_{\text {green }}\right)$ that established on narrow or broad bands showed no obvious difference in $\mathrm{CNC}$ retrieval, broadband indices were suitable for $\mathrm{CNC}$ assessment as well. Overall, our study suggests that NDVI-like index was the optimal indicator for winter wheat $\mathrm{CNC}$ retrieval. 


\section{Acknowledgements}

This study was supported by National Natural Science Foundation of China (41571354, 41501468, 41301389 and 41301375). Also, this study benefited from a contribution granted by the scientific cooperation program between the Italian National Research Council (CNR) and Chinese Academy of Sciences (CAS). The authors thank the reviewers for their helpful comments and suggestions. We also would like to acknowledge those who helped with the field campaign at the National Experimental Station for Precision Agriculture and the staff there for the management of the test flight test and the crop planting.

\section{References}

Baret, F., Houles, V., Guérif, M., 2007. Quantification of plant stress using remote sensing observations and crop models: the case of nitrogen management. J. Exp. Bot. 58, 869-880.

Bremner, J., 1960. Determination of nitrogen in soil by the Kjeldahl method. J. Agric. Sci. 55, 11-33.

Clevers, J.G., Gitelson, A.A., 2013. Remote estimation of crop and grass chlorophyll and nitrogen content using red-edge bands on Sentinel-2 and-3. Int. J. Appl. Earth Obs. Geoinf. 23, 344-351.

Clevers, J.G., Kooistra, L., 2012. Using hyperspectral remote sensing data for retrieving canopy chlorophyll and nitrogen content. IEEE J. Sel. Top. Appl. Earth Obs. Remote Sens. 5, 574-583.

Darvishzadeh, R., Atzberger, C., Skidmore, A., Schlerf, M., 2011. Mapping grassland leaf area index with airborne hyperspectral imagery: a comparison study of statistical approaches and inversion of radiative transfer models. ISPRS J. Photogramm. Remote Sens. 66, 894-906.

Dash, J., Curran, P., 2004. The MERIS terrestrial chlorophyll index. Int. J. Remote Sens. 25, 5403-5413.

Ercoli, L., Mariotti, M., Masoni, A., Massantini, F., 1993. Relationship between nitrogen and chlorophyll content and spectral properties in maize leaves. Eur. J. Agron. 2, 113-117.

Feng, W., Guo, B.-B., Wang, Z.-J., et al., 2014. Measuring leaf nitrogen concentration in winter wheat using double-peak spectral reflection remote sensing data. Field Crops Res. 159, 43-52.

Ferguson, R., Hergert, G., Schepers, J., Gotway, C., Cahoon, J., Peterson, T., 2002. Site-specific nitrogen management of irrigated maize. Soil Sci. Soc. Am. J. 66, 544-553.

Gao, J., 2006. Experimental Guidance for Plant Physiology. Higher Education Press, Beijing.

Gitelson, A.A., Vina, A., Ciganda, V., et al., 2005. Remote estimation of canopy chlorophyll content in crops. Geophys. Res, Lett, 32.

Hansen, P., Schjoerring, J., 2003. Reflectance measurement of canopy biomass and nitrogen status in wheat crops using normalized difference vegetation indices and partial least squares regression. Remote Sens. Environ. 86, 542-553.

Hatfield, J., Gitelson, A.A., Schepers, J.S., Walthall, C., 2008. Application of spectral remote sensing for agronomic decisions. Agron. J. 100, S31-S-117.
Inoue, Y., Sakaiya, E., Zhu, Y., Takahashi, W., 2012. Diagnostic mapping of canopy nitrogen content in rice based on hyperspectral measurements. Remote Sens. Environ. 126, 210-221.

Ladha, J.K., Pathak, H., Krupnik, T.J., Six, J., van Kessel, C., 2005. Efficiency of fertilizer nitrogen in cereal production: retrospects and prospects. Adv. Agron. 87, 85-156.

Lemaire, G., 1997. Diagnosis of the Nitrogen Status in Crops. SpringerVerlag.

Liu, L. Hyperspectral remote sensing application in precision agriculture. Postdoctoral Report 4245, 2002.

Nobel, P.S., 2009. Physicochemical and Environmental Plant Physiology, Fourth ed. Elsevier Academic Press, New York.

Oppelt, N., Mauser, W., 2004. Hyperspectral monitoring of physiological parameters of wheat during a vegetation period using AVIS data. Int. J. Remote Sens. 25, 145-159.

Schlemmer, M., Gitelson, A., Schepers, J., et al., 2013. Remote estimation of nitrogen and chlorophyll contents in maize at leaf and canopy levels. Int. J. Appl. Earth Obs. Geoinf. 25, 47-54.

Sims, D.A., Gamon, J.A., 2002. Relationships between leaf pigment content and spectral reflectance across a wide range of species, leaf structures and developmental stages. Remote Sens. Environ. 81, $337-$ 354.

Tian, Y., Yao, X., Yang, J., Cao, W., Hannaway, D., Zhu, Y., 2011. Assessing newly developed and published vegetation indices for estimating rice leaf nitrogen concentration with ground-and spacebased hyperspectral reflectance. Field Crops Res. 120, 299-310.

Viña, A., Gitelson, A.A., 2005. New developments in the remote estimation of the fraction of absorbed photosynthetically active radiation in crops. Geophys. Res. Lett. 32.

Viña, A., Gitelson, A.A., Nguy-Robertson, A.L., Peng, Y., 2011. Comparison of different vegetation indices for the remote assessment of green leaf area index of crops. Remote Sens. Environ. 115, 34683478.

Wang, Z., Wang, J., Liu, L., Huang, W., Zhao, C., Lu, Y., 2005. Estimation of nitrogen status in middle and bottom layers of winter wheat canopy by using ground-measured canopy reflectance. Commun. Soil Sci. Plant Anal. 36, 2289-2302.

Wu, J., Wang, D., Rosen, C.J., Bauer, M.E., 2007. Comparison of petiole nitrate concentrations, SPAD chlorophyll readings, and QuickBird satellite imagery in detecting nitrogen status of potato canopies. Field Crops Res. 101, 96-103.

Xie, Q., Huang, W., Liang, D., et al., 2014. Leaf area index estimation using vegetation indices derived from airborne hyperspectral images in winter wheat. IEEE J. Sel. Top. Appl. Earth Obs. Remote Sens. 7, 3586-3594.

Yoder, B.J., Pettigrew-Crosby, R.E., 1995. Predicting nitrogen and chlorophyll content and concentrations from reflectance spectra (400-2500 nm) at leaf and canopy scales. Remote Sens. Environ. 53, 199-211.

Zhao, C., Wang, Z., Wang, J., Huang, W., 2012. Relationships of leaf nitrogen concentration and canopy nitrogen density with spectral features parameters and narrow-band spectral indices calculated from field winter wheat (Triticum aestivum L.) spectra. Int. J. Remote Sens. $33,3472-3491$. 